\title{
Cost-effectiveness of allopurinol versus febuxostat in the treatment of gout patients: A systematic review
}

\author{
Aziz Rezapour ${ }^{1}$, Saeide Alidoost*1${ }^{1}$, Asra Asgharzadeh ${ }^{2}$, Zeynab Farhadi ${ }^{1}$, Najme Khodadadi ${ }^{1}$, Roghayeh Mohammadi \\ Bakhsh $^{1}$, Razieh Sepehrian ${ }^{1}$, Morteza Salemi ${ }^{1}$, Masood Taheri Mirghaed ${ }^{1}$, Masoud Behzadifar ${ }^{1}$, Rahim Sohrabi ${ }^{1}$ \\ Received: 11 Aug 2018 \\ Published: 30 Apr 2020
}

\begin{abstract}
Background: In recent years, increased longevity, poor dietary habits, and the rising prevalence of metabolic syndrome and hypertension have increased the prevalence of gout. Gout significantly increases direct and indirect costs and reduces the quality of life. Allopurinol and febuxostat are the most commonly used drugs for reducing uric acid levels and controlling this disease with different cost-effectiveness. The present systematic review compares the cost-effectiveness of these drugs.

Methods: This was a systematic review of economic evaluations. Cochrane CENTRAL, Web of Science, PubMed, Embase, and the Cost-Effectiveness Analysis (CEA) Registry were searched up to April 30, 2018, based on the specific search strategy of each database. Keywords used in the search include gout, cost-effectiveness, allopurinol, and febuxostat in MeSH and free-text forms. Screening of identified studies, data extraction, and quality assessment were done independently by 2 reviewers. The quality of studies was assessed based on Drummond Checklist. Finally, a qualitative analysis was done to analyze the results.

Results: A total of 94 studies were identified through database search and the review of references. After screening the titles, abstracts, and full-texts, 6 economic evaluations were included in the review. The majority of the studies had been conducted in the US using the Markov model, within a 5-year horizon, and from the payer's perspective, with the quality of life as a measure of effectiveness. In most studies, the incremental cost-effectiveness ratios (ICERs) of febuxostat per quality-adjusted life year (QALY) were below the threshold (10 000\$/QALY and $30000 € / Q A L Y)$.

Conclusion: Febuxostat has been shown to be more cost-effective than allopurinol in all treatment sequences in studies that have used uric acid levels as the measure of effectiveness. Furthermore, in studies with the quality of life as the measure of effectiveness, febuxostat has been shown to be very cost-effective as the second-line treatment.
\end{abstract}

Keywords: Gout, Economic evaluation, Cost-Effectiveness, Allopurinol, Febuxostat, Systematic review

Conflicts of Interest: None declared

Funding: Health Management and Economics Research Center, Iran University of Medical Sciences

\section{*This work has been published under CC BY-NC-SA 1.0 license.}

Copyright $₫$ Iran University of Medical Sciences

Cite this article as: Rezapour A, Alidoost S, Asgharzadeh A, Farhadi Z, Khodadadi N, Mohammadi Bakhsh R, Sepehrian R, Salemi M, Taheri Mirghaed M, Behzadifar M, Sohrabi R. Cost-effectiveness of allopurinol versus febuxostat in the treatment of gout patients: A systematic review. Med J Islam Repub Iran. 2020 (30 Apr);34:41. https://doi.org/10.34171/mjiri.34.41

\section{Introduction}

Gout is a debilitating and painful disease that can cause

acute or chronic arthritis due to hyperuricemia. In recent

Corresponding author:Dr Saeide Alidoost, alidoost.s@iums.ac.ir

1. Department of Health Services Management, School of Health Management and Information Sciences, Iran University of Medical Sciences, Tehran, Iran

2. Health Technology Assessment Group (HTAG), Universal Scientific Education and Research Network (USERN), Tehran, Iran $\uparrow$ What is "already known" in this topic:

Allopurinol and febuxostat are urate-lowering drugs used for the long-term treatment of gout through reducing the uric acid levels. More studies have indicated cost-effectiveness of febuxostat in reducing serum urate concentration and showed that it allevilates gout flares better than allopurinol. However, related studies have reported conflicting results about the cost-effectiveness of these drugs.

\section{$\rightarrow$ What this article adds:}

Febuxostat is more cost-effective than allopurinol in all treatment sequences in studies which have used uric acid level as the measure of effectiveness. In addition, febuxostat has been shown to be more costeffective as the second-line treatment in studies with the quality of life as the measure of effectiveness. 
years, the prevalence of gout has increased due to increased longevity, poor dietary habits, and increase in related diseases such as metabolic syndrome and hypertension. The prevalence of this disease doubled between 1990 and 2010 (1-3). Epidemiological studies have shown that the prevalence of gout in all countries increases with age, with the highest prevalence observed in people over 40 and, especially, over 60 years (2-8). A study in Hong Kong found that $5 \%$ of individuals aged $45-59$ years and $6 \%$ of those older than 60 years had gout (4). There has been a recent renewal of interest in gout and its management and costs due to the following factors: the rise in its incidence and prevalence; recognition of its unfavorable long-term outcomes (debilitation and reduced quality of life); new knowledge about mechanisms underlying the expression of the disease; and new interventions to control painful acute episodes and the chronic progressive and disabling features of gout $(9,10)$. This disease has a significant impact on direct costs (outpatient visits, diagnosis, medication, and inpatient stays) and indirect costs such as productivity loss. These costs (over 90\%) are mostly direct medication costs $(11,12)$.

Therefore, the best approach to deal with this disease is to implement strategies to improve patient outcomes while reducing the economic burden of gout for patients, payers, and governments. The most important strategies for cost reduction are as follow: increasing awareness of adherence to treatment, as noncompliance can cause progression of the disease and increase its costs; raising awareness in primary care physicians about the latest guidelines and interventions for treatment of gout; and prescription of optimal (traditional and modern) treatments to prevent and manage gout flares (10).

Medications used in the treatment of gout include antiinflammatory and urate-lowering drugs that are prescribed to alleviate the symptoms of an acute flare and prevent recurrences. Urate-lowering drugs such as probenecid, which increases uric acid excretion, and allopurinol and febuxostat, which lower uric acid levels, are used for longterm treatment $(10,13-15)$. Febuxostat was introduced in 2009 in the US as an alternative to allopurinol (16). Studies on the effectiveness of allopurinol and febuxostat in reducing serum urate concentration and alleviating gout flares have found different results, with most studies indicating that febuxostat is more effective than allopurinol in reducing serum urate concentration $(17,18)$. Costeffectiveness analyses have also shown differences in the costs of these drugs, with most studies reporting that treatment with febuxostat is more expensive than allopurinol by more than $\$ 1000(15,19-22)$. On the other hand, the only systematic review on the cost-effectiveness of gout medications by Kydd et al (2014) showed that the evidence on urate-lowering drugs was very limited and only 3 studies were included in the review (23). Therefore, a review of various studies on the costs and effects of allopurinol and febuxostat on gout outcomes seems necessary. Given that numerous studies have been done on the cost-effectiveness of these drugs, and the necessity to make the final decision about the suitable drug for the treatment and control of gout, this study aimed to compare the cost-effectiveness of gout medications through a systematic review of the relevant economic evaluations.

\section{Methods}

\section{Literature Search}

Cochrane CENTRAL, Web of Science, PubMed, Embase, and the Cost-Effectiveness Analysis (CEA) Registry were searched between January 1, 2000 and April 30, 2018 , based on the specific search strategy of each database (Appendix 1) and using a combination of keywords and Medical Subject Headings (MeSH). In addition to electronic search, the reference lists of relevant studies were reviewed to find more studies.

\section{Study selection}

First, the titles and abstracts of the identified studies were independently examined by 2 reviewers, and economic evaluations related to gout treatments were selected. Next, the full-texts of all eligible studies were examined in the screening phase and discrepancies between the reviewers were resolved by consulting a third person and consensus.

\section{Eligibility criteria}

Eligible studies included randomized controlled trials (RCT) studies conducted between 2000 and 2018 that have examined the cost-effectiveness of allopurinol (as the comparator) and febuxostat (as the intervention) in elderly patients in the last 3 stages of gout (acute, intercritical, and chronic). The followings were excluded from this review: studies on other than economic evaluations; studies on adolescents' populations and on patients with asymptomatic hyperuricemia; other reviews; subjects related to the safety and effectiveness of gout medications; conference abstracts; book chapters; and letters/editorials. However, cost-effectiveness studies were included because the effects of the medicines used to treat gout are different and the aim of the present study was to consider nonmonetary outcomes and all health outcomes, not just a measure of utility.

\section{Data extraction and quality assessment}

Data were extracted from elligible studies based on the objectives of the study and were independently checked by a third reviewer. Data included author, publication year, country of study, model, perspective, time horizon, outcome measures (effectiveness outcomes), demographic characteristics, intervention type, comparator, costs, incremental cost-effectiveness ratios (ICERs), and key findings. Data extraction was done independently by the 2 researchers (ZF \& NJH) and discrepancies were resolved by consulting a third person $(\mathbb{R M})$ and consensus. ICERs were reported accurately, as they were presented in the articles and were not adjusted by a year or purchasing power parity. Qualitative data analysis was performed following data extraction.

Quality of the studies was assessed using the Drummond 10-item Checklist, which is one of the most comprehensive tools for quality assessment of economic evaluations and has been recommended by the Cochrane 
Handbook for Systematic Reviews of Interventions. It consists of 10 items with 4 options: yes, no, not clear (NC), and not appropriate (NA). The quality score of each study is based on the number of yes answers, and studies with a score above 7 are of high quality. Studies with quality scores between 3 and 7 or less than 3 are, respectively, of medium or low quality $(24,25)$. Quality assessment was performed by 2 researchers independently (NKH, RM, ZF, and/or SA), and discrepancies were resolved by consulting a third person and consensus.

\section{Results}

Study selection

A total of 89 studies were identified through database searches and 5 studies through reference lists of relevant studies. After removing redundant cases, the titles and abstracts of 51 studies were examined by 2 researchers independently and based on the research question; finally, the full-texts of 15 economic evaluations were examined. At this stage, noneconomic evaluations, such as efficacy and safety studies $(n=20)$, conference abstracts $(n=3)$, reports $(n=2)$, economic evalluations other than costeffectiveness analysis $(\mathrm{n}=2)$, and studies examining either allopurinol or febuxostat $(n=2)$, were removed, and the 6 remaining studies were systematically reviewed. The PRISMA flowchart is presented in Figure 1.

\section{Quality of the studies}

Quality was assessed using the Drummond 10-item Checklist. The results showed that all studies were of relatively high quality, with 4 high-quality studies (scores higher than 7) and 2 moderate quality studies (a score of 6 out of 10). The results of the quality assessment are presented in Table 1 by each item in the Drummond Checklist.

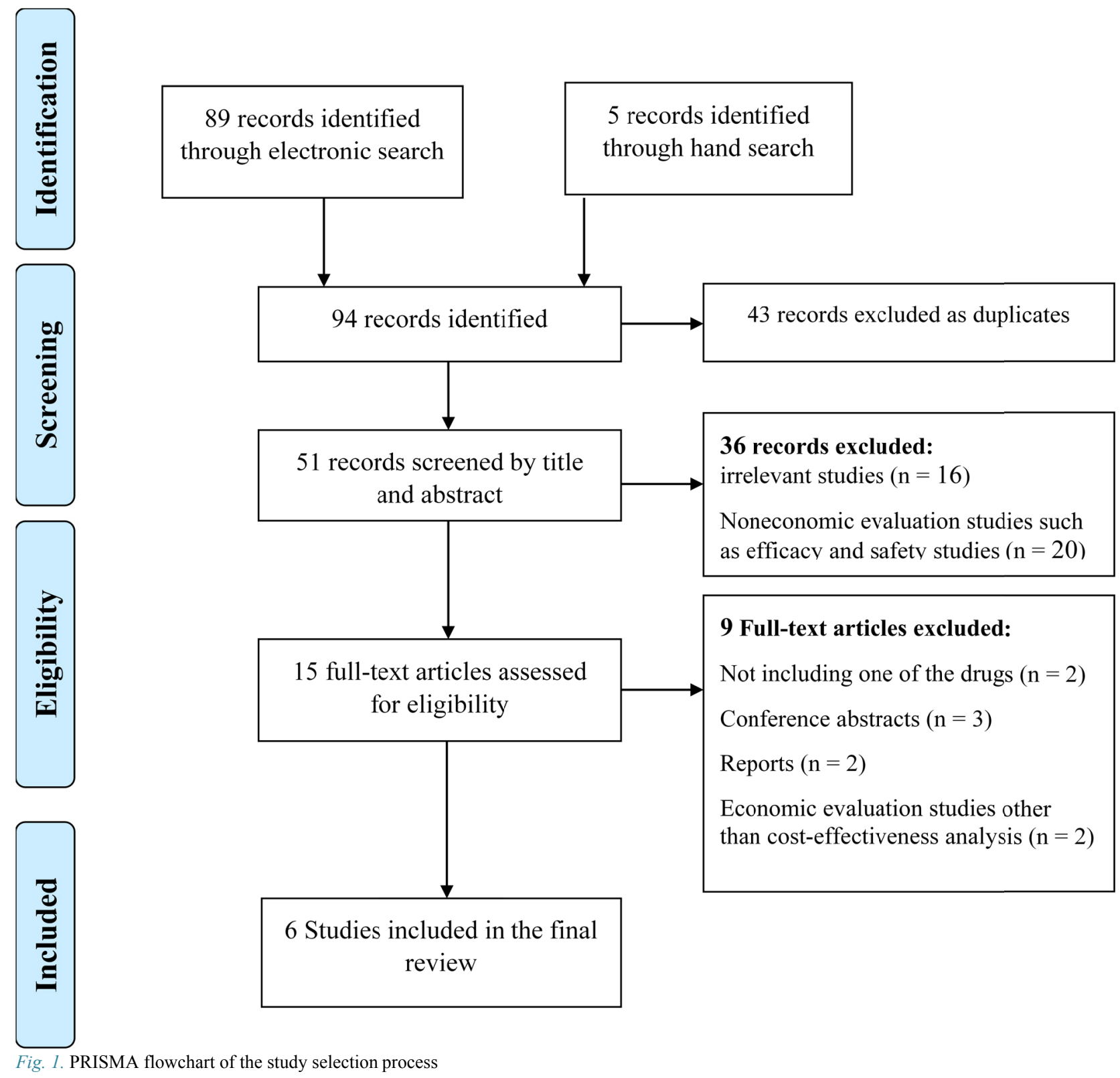




\begin{tabular}{|c|c|c|c|c|c|c|c|}
\hline \multirow[t]{2}{*}{$\begin{array}{l}\text { Item } \\
\text { no. }\end{array}$} & \multirow[t]{2}{*}{ Item } & \multicolumn{6}{|c|}{$\begin{array}{c}\text { Quality of included studies } \\
\text { (Yes/No/NC/NA) }\end{array}$} \\
\hline & & 1 & 2 & 3 & 4 & 5 & 6 \\
\hline 1 & Was a well-defined question posed in answerable form? & Yes & Yes & Yes & Yes & Yes & Yes \\
\hline 2 & $\begin{array}{l}\text { Was a comprehensive description of the competing alternatives given (i.e. can you tell who } \\
\text { did what to whom, where, and how often)? }\end{array}$ & Yes & Yes & Yes & Yes & Yes & Yes \\
\hline 3 & Was the effectiveness of the programme or services established & Yes & Yes & Yes & Yes & Yes & Yes \\
\hline 4 & Were all the important and relevant costs and consequences for each alternative identified & Yes & Yes & Yes & Yes & Yes & No \\
\hline 5 & $\begin{array}{l}\text { Were costs and consequences measured accurately inappropriate physical units (e.g. hours } \\
\text { of nursing time, number of physician visits, lost work-days, gained life years)? }\end{array}$ & Yes & Yes & Yes & No & Yes & No \\
\hline 6 & Were the cost and consequences valued credibly & Yes & Yes & Yes & NA & Yes & No \\
\hline 7 & Were costs and consequences adjusted for differential timing? & Yes & Yes & Yes & No & No & Yes \\
\hline 8 & Was an incremental analysis of costs and consequences of alternatives performed & Yes & Yes & Yes & No & Yes & Yes \\
\hline 9 & Was allowance made for uncertainty in the estimates of costs and consequences & Yes & Yes & Yes & Yes & Yes & Yes \\
\hline \multirow[t]{2}{*}{10} & Did the presentation and discussion of study results include all issues of concern to users? & Yes & Yes & Yes & Yes & Yes & NA \\
\hline & Total & 10 & 10 & 10 & 6 & 9 & 6 \\
\hline
\end{tabular}

\section{Data extraction}

The results showed a limited number of economic evaluations that compared the cost-effectiveness of allopurinol and febuxostat in patients with gout. Four studies (67\%) have been conducted in the US, one in Spain $(17 \%)$, and one in Scotland (17\%). The majority of the studies were conducted from a health care payer perspective (67\%), while the rest were conducted from a health system perspective. Four studies had a 5-year time horizon, while the other 2 were conducted in a 1-year and lifetime horizon. The Markov model was the most common model used in every study, except in Meltzer et al (2012) and Smolen et al studies (2015). In 5 out of 6 studies, cost-effectiveness was measured based on randomized clinical trials. In every study, except in Meltzer (2012) and Smolen et al (2015) studies, quality of life was examined as the outcome of effectiveness. The details of these studies are provided in Table 2.

\section{Data analysis}

To compare allopurinol with febuxostat, ICERs were calculated in every study, except in Smolen et al's study (2015), and in all these studies, medication cost was considered as the most important direct cost of patients with gout. Other direct costs, including costs related to sideeffects, and other nonmedication costs, including the costs of outpatient, inpatient, and emergency visits, have been examined in a number of studies. In all these studies, the ICER for febuxostat as the second-line treatment was less than that of allopurinol, indicating the high costeffectiveness of this drug as a complimentary line for allopurinol. However, studies have shown that using this drug as the first-line treatment or increasing its dose in subsequent stages is not cost-effective. However, in the study of Smolen et al, its cost-effectiveness for 2 ICERs, eg, per patient reaching target sUA and per flare avoided, has been established (22). The results of economic evaluations reviewed in this study are presented in Table 3.

\begin{tabular}{|c|c|c|c|c|c|c|c|c|}
\hline Reference & Author & Year & Country & Model used & Perspective & $\begin{array}{c}\text { Time } \\
\text { horizon }\end{array}$ & $\begin{array}{l}\text { Outcome Measure(s)/ } \\
\text { Source of data }\end{array}$ & Population \\
\hline (26) & Beard & 2013 & Scotland & $\begin{array}{l}\text { Markov co- } \\
\text { hort model }\end{array}$ & $\begin{array}{l}\text { National } \\
\text { Health } \\
\text { System }\end{array}$ & 5 years & $\begin{array}{l}\text { QALY/Multiple RCTs, } \\
\text { Individual studies, and } \\
\text { British National Formulary }\end{array}$ & $\begin{array}{l}\text { Adults with chronic and } \\
\text { uncontrolled Gout }\end{array}$ \\
\hline (19) & Gandhi & 2015 & $\begin{array}{l}\text { United } \\
\text { States }\end{array}$ & $\begin{array}{l}\text { Markov co- } \\
\text { hort model }\end{array}$ & payer & 5 years & $\begin{array}{l}\text { QALY/ Multiple RCTs, } \\
\text { Individual studies, Medi- } \\
\text { care fee schedules, the } \\
\text { RED BOOK and expert } \\
\text { consultation }\end{array}$ & $\begin{array}{l}\text { Adult gout patients } \\
\text { (mean age: } 43 \text { years) }\end{array}$ \\
\hline (20) & Jutkowitz & 2014 & $\begin{array}{l}\text { United } \\
\text { States }\end{array}$ & $\begin{array}{l}\text { Markov co- } \\
\text { hort model }\end{array}$ & payer & Lifetime & $\begin{array}{l}\text { QALY/ Published litera- } \\
\text { ture and expert opinion }\end{array}$ & $\begin{array}{c}\text { patients aged } 53 \text { years } \\
\text { with gout }\end{array}$ \\
\hline (27) & Meltzer & 2012 & $\begin{array}{l}\text { United } \\
\text { States }\end{array}$ & $\begin{array}{c}\text { decision } \\
\text { analytic model }\end{array}$ & payer & 1 year & $\begin{array}{l}\text { serum uric acid level, skin } \\
\text { rash, and liver abnormali- } \\
\text { ties/ Multiple RCTs }\end{array}$ & Adult gout patients \\
\hline (22) & Smolen & 2015 & $\begin{array}{l}\text { United } \\
\text { States }\end{array}$ & $\begin{array}{l}\text { cost- } \\
\text { effectiveness } \\
\text { mode }\end{array}$ & $\begin{array}{l}\text { private- } \\
\text { payer }\end{array}$ & 5 years & $\begin{array}{l}\text { clinical outcomes/ Multi- } \\
\text { ple RCTs, Individual stud- } \\
\text { ies, government sources } \\
\text { and expert opinion }\end{array}$ & $\begin{array}{c}\text { gout population over } \\
\text { age } 65\end{array}$ \\
\hline (9) & $\begin{array}{l}\text { Perez- } \\
\text { Ruiz }\end{array}$ & 2016 & Spain & $\begin{array}{l}\text { Markov co- } \\
\text { hort model }\end{array}$ & $\begin{array}{l}\text { National } \\
\text { Health } \\
\text { System }\end{array}$ & 5 years & $\begin{array}{l}\text { Clinical outcomes and } \\
\text { QALY/ Multiple RCTs, } \\
\text { Individual studies and } \\
\text { government sources }\end{array}$ & Adult gout patients \\
\hline
\end{tabular}


Table 3. The results of the reviewed studies

\begin{tabular}{|c|c|c|c|c|c|c|}
\hline \multirow[t]{2}{*}{$\begin{array}{l}\text { Author, year/ } \\
\operatorname{Re}\end{array}$} & \multicolumn{3}{|c|}{$\begin{array}{l}\text { Direct health-related } \\
\text { costs }\end{array}$} & \multirow[t]{2}{*}{ Intervention } & \multirow[t]{2}{*}{ Comparator } & \multirow[t]{2}{*}{ ICER } \\
\hline & $\mathrm{DC}^{1}$ & $\mathrm{CAE}^{2}$ & $\mathrm{NPC}^{3}$ & & & \\
\hline $\begin{array}{l}\text { Stephen M. } \\
\text { Beard /2013/ } \\
(26)\end{array}$ & $*$ & $*$ & $*$ & $\begin{array}{c}\text { febuxostat } 80 \\
\text { mg/120 mg as a } \\
\text { second-line } \\
\text { treatment after } \\
\text { allopurinol } \\
\text { (allopurinol- } \\
\text { febuxostat } \\
\text { sequential therapy) }\end{array}$ & $\begin{array}{c}\text { allopurinol } \\
300 \mathrm{mg} \text { alone }\end{array}$ & $£ 3,578$ per QALY \\
\hline $\begin{array}{l}\text { Pranav K. } \\
\text { Gandhi/ } \\
\text { 2014/ (19) }\end{array}$ & $*$ & & * & $\begin{array}{c}\text { Febuxostat } 80 \mathrm{mg} \\
\text { alone }\end{array}$ & $\begin{array}{c}\text { Allopurinol } \\
300 \mathrm{mg} \text { alone }\end{array}$ & $\begin{array}{l}\$ 6,322 \text { per achievement of a } \\
\text { sUA level }<6 \mathrm{mg} / \mathrm{dL})\end{array}$ \\
\hline
\end{tabular}

2014/ (19)

sUA level $<6 \mathrm{mg} / \mathrm{dL}$

The best first-line option for

lowering serum uric acid is

Allopurinol at $300 \mathrm{mg} / \mathrm{day}$, and,

if ineffective, treatment strategy

can switch to Febuxostat at 80 or $120 \mathrm{mg} /$ day.

Febuxostat at 80 or $120 \mathrm{mg} /$ day is the cost-effective strategy second-line treatment, and its ICER per QALY is below the threshold $(\$ 10,000)$.

From a payer's perspective, Febuxostat is more costeffective than Allopurinol and its ICER per treatment success is below the threshold $(\$ 10,000)$.

\begin{tabular}{|c|c|c|c|c|c|c|}
\hline $\begin{array}{l}\text { Eric Jutko- } \\
\text { witz/ 2014/ } \\
(20)\end{array}$ & $*$ & $*$ & $\begin{array}{l}\text { Dose-escalation } \\
\text { allopurinol- } \\
\text { febuxostat } \\
\text { sequential therapy } \\
\text { Dose-escalation } \\
\text { febuxostat- allopu- } \\
\text { rinol sequential } \\
\text { therapy }\end{array}$ & $\begin{array}{l}\text { Allopurinol } \\
\text { alone }\end{array}$ & $\$ 39400$ per QALY & $\begin{array}{l}\text { Dose-escalation Febuxostat and } \\
\text { dose-escalation Febuxostat- } \\
\text { Allopurinol sequential therapy } \\
\text { are not cost-effective strategies, } \\
\text { though they may be highly } \\
\text { effective. However, Febuxostat } \\
\text { is a suitable second-line option, } \\
\text { and dose-escalation. }\end{array}$ \\
\hline
\end{tabular}

Dose-escalation of $\quad \$ 322800$ per QALY

Febuxostat $(<120 \mathrm{mg})$

\begin{tabular}{|c|c|c|c|c|c|c|}
\hline $\begin{array}{l}\text { Michele } \\
\text { Meltzer/ } \\
2012 /(27)\end{array}$ & $*$ & 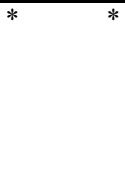 & $\begin{array}{c}\text { Allopurinol } 300 \\
\text { mg -febuxostat } \\
80-240 \mathrm{mg} \\
\text { sequential therapy }\end{array}$ & $\begin{array}{l}\text { Allopurinol } \\
\text { alone } 300 \mathrm{mg}\end{array}$ & Not mentioned & $\begin{array}{l}\text { Allopurinol is a suitable first- } \\
\text { line strategy, but if it is ineffec- } \\
\text { tive in lowering serum urate } \\
\text { levels in some patients, Febux- } \\
\text { ostat is prescribed as the sec- } \\
\text { ond-line option. }\end{array}$ \\
\hline
\end{tabular}

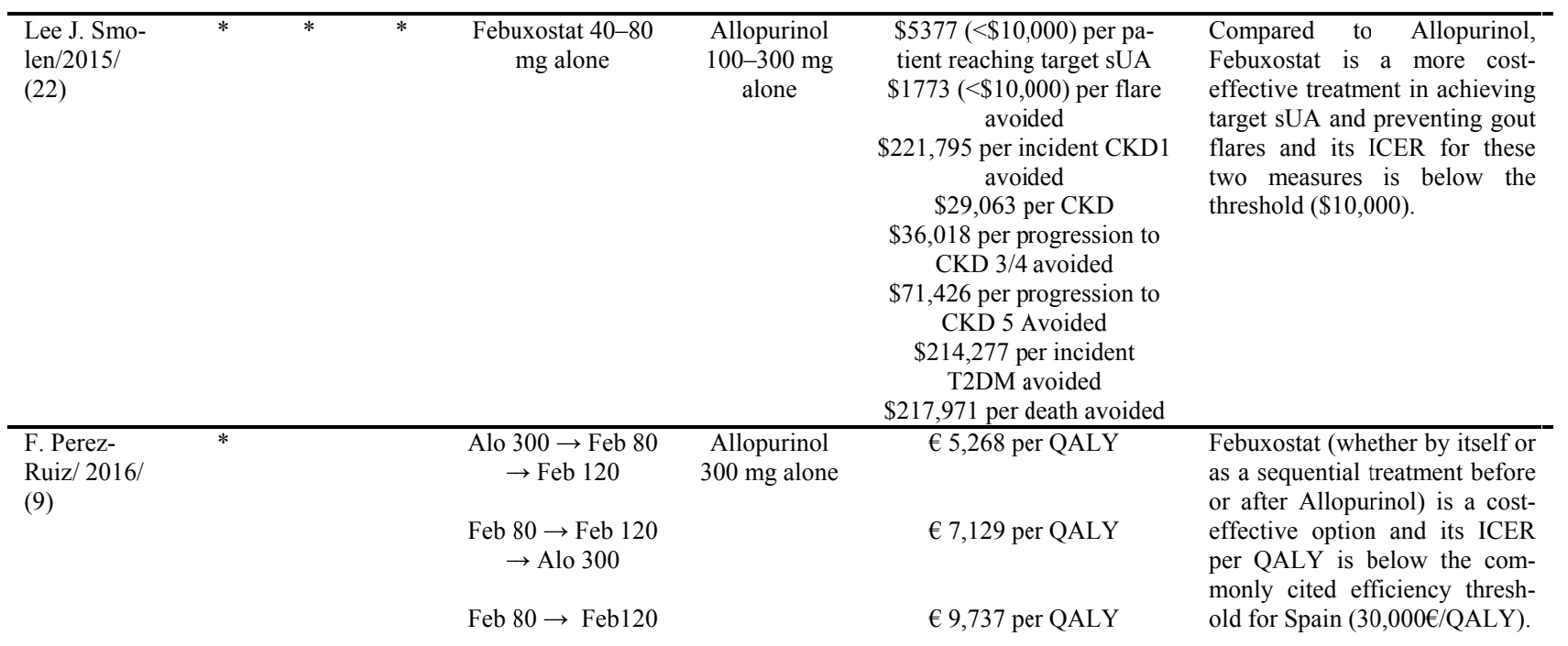

1. Drug Costs, 2. Costs Associated with Adverse Events, 3. Nonpharmacologic Costs, 4. Chronic Kidney Disease

\section{Discussion}

The aim of the present study was to systematically review economic evaluations that examine the costeffectiveness of allopurinol and febuxostat in the treatment of gout. The results showed that 6 studies have examined the cost-effectiveness of these 2 drugs in the population of interest.
Evidence suggests that in most economic evaluations related to gout medications, quality of life is examined as the measure of effectiveness, and only a limited number of studies have mentioned clinical indicators and the sideeffects of drugs. Allopurinol and febuxostat have different effects on clinical outcomes and quality of life, and the high effectiveness of febuxostat in lowering serum urate levels has been observed. The results of most studies re- 
vealed that other clinical outcomes, including gout flares and side-effects (eg, diarrhea, headache), are similar in febuxostat and allopurinol treatments $(16,17,28)$. However, some studies have reported conflicting results, suggesting that febuxostat has fewer side-effects than allopurinol (14), while some studies have reported a higher prevalence of gout flares in patients receiving febuxostat compared to allopurinol, which may be due to the very fast reduction in serum uric acid levels $(29,30)$. A 2011 systematic review, which included 21 studies, examined achieving target used as a clinical outcome, along with the side-effects of allopurinol and febuxostat, and showed that the latter has no effect on the risk of gout flares (14). In addition, a 2013 systematic review and meta-analysis was conducted on the efficacy and safety of febuxostat versus allopurinol, with 7 studies and 25 associated publications. The results of that systematic review showed that although febuxostat increases the likelihood of achieving a target serum uric acid of $<6 \mathrm{mg} / \mathrm{dL}$, there is no evidence suggesting that it is superior to allopurinol for clinical outcomes, and given its higher cost, febuxostat should not be routinely used for acute gout. Given the limitations of this review and the high heterogeneity of the studies, the reported results must be cited with caution (30).

Studies included in the present systematic review addressed the direct costs of gout medications and examined other costs such as those related to side-effects, gout flares, diagnosis, and outpatient visits. However, indirect costs were not included in the calculations for a variety of reasons. The results of these studies showed that the cost of per patient who took febuxostat was higher than that the cost per patient who tool allopurinol, and it included all direct costs associated with each treatment (medication costs and nonmedication costs related to disease control and management). The costs were mainly medication costs rather than diagnostic or management costs (21). The results of Smolen et al study (2016) showed that the total cost per patient was $\$ 1264$ higher for febuxostat than for allopurinol (22).

The results of Beard et al (2014) on the costeffectiveness of febuxostat in chronic gout patients showed that the ICER per QALY of febuxostat in a 5-year horizon was \$3578, which is below the accepted threshold. Accordingly, they suggested febuxostat as a costeffective and suitable second-line option after allopurinol (26). Other studies that examined the quality of life as the measure of effectiveness have found febuxostat as a costeffective drug for second-line treatment. Smolen et al (2016) showed that the cost-effectiveness ratio of febuxostat to allopurinol is $\$ 5377$ per patient who has reached the required uric acid level, $\$ 1773$ per flare avoided, \$221 795 per incident CKD avoided, and \$29 063 per CKD progression avoided, indicating that febuxostat may be a cost-effective alternative to allopurinol, especially for patients with CKD stages 3 or $4(22,29)$.

Studies have shown that limiting gout treatment to the first-line option, eg, the use of either allopurinol or febuxostat, is not clinically and economically cost-effective, and a combination of these drugs can be used at different stages of the disease and based on the conditions of the pa- tient. The results of Jutkowitz et al (2014) suggested that administration of allopurinol or febuxostat alone are not cost-effective; however, allopurinol-febuxostat sequential therapy increases the cost-effectiveness of the treatment (20).

Some studies have shown that febuxostat is more costeffective as a second-line option and choosing it as the first-line treatment is not cost-effective. However, studies that have examined the reduction in serum uric acid as the measure of effectiveness have shown that febuxostat is more cost-effective than allopurinol in all conditions and its ICER is lower than the efficiency threshold (9). The results of these studies are consistent with the conclusion of the National Institute for Clinical Effectiveness (NICE) that febuxostat is used as an option for the management of chronic hyperuricemia in gout only for those who are intolerant to allopurinol or for whom allopurinol is contraindicated (31).

Although studies included in the present review were of high quality, it must be noted that this review had some limitations. First, it only focused on the cost-effectiveness of the 2 interventions in elderly gout patients and excluded other economic evaluations. In addition, the small number of studies performed in this area (primarily due to the introduction of febuxostat in 2009) limited the scope of the review, and the results must be interpreted with caution. Generalization of the results of studies with small samples to those of larger populations requires that numerous variables be taken into account, which could not be achieved due to the scarcity of relevant studies. Moreover, the outcomes examined in the scant literature are very limited; thus, only some of the effects of these interventions were addressed in this review.

\section{Conclusion}

Studies that have examined reduction in serum uric acid as the measure of effectiveness have shown that febuxostat is more cost-effective than allopurinol in all treatment sequences. However, studies that have used quality of life as the measure of effectiveness have shown that febuxostat was very cost-effective as the second-line option, but prescribing it as the first-line treatment, increasing its dose, or switching to allopurinol is not cost-effective. However, given the limited number of studies conducted in this area, further primary studies with larger sample sizes are needed to achieve more accurate results.

\section{Acknowledgments}

The authors would like to thank the Health Management and Economics Research Center, Iran University of Medical Sciences, for financially supporting this study.

\section{Conflict of Interests}

The authors declare that they have no competing interests.

\section{References}

1. Chowalloor $\mathrm{P}$, Keen $\mathrm{H}$, Inderjeeth $\mathrm{C}$, Chowalloor $\mathrm{P}$, Keen $\mathrm{H}$, Inderjeeth C. Gout in the elderly. OA Elderly Medicine. 2013;1(1):2. 2. Kim KY, Schumacher HR, Hunsche E, Wertheimer AI, Kong SX. A 
literature review of the epidemiology and treatment of acute gout. Clin Ther. 2003;25(6):1593-617.

3. Smith E, Diaz-Torne C, Perez-Ruiz F, March L. Epidemiology of gout: an update. Best Pract Res Clin Rheumatol. 2010;24(6):811-27.

4. Kuo CF, Grainge MJ, Zhang W, Doherty M. Global epidemiology of gout: prevalence, incidence and risk factors. Nat Rev Rheumatol. 2015;11(11):649-62.

5. Nuki G, Simkin PA. A concise history of gout and hyperuricemia and their treatment. Arthritis Res Ther. 2006;8(1):1.

6. Roddy E, Doherty M. Gout. Epidemiology of gout. Arthritis Res Ther 2010;12(6):223

7. Roddy E, Zhang W, Doherty M. The changing epidemiology of gout. Nat Rev Rheumatol. 2007;3(8):443-9.

8. Zhu Y, Pandya BJ, Choi HK. Prevalence of gout and hyperuricemia in the US general population: the National Health and Nutrition Examination Survey 2007-2008. Arthritis Rheumatol. 2011;63(10):3136-41.

9. Perez-Ruiz F, Díaz-Torné C, Carcedo D. Cost-effectiveness analysis of febuxostat in patients with gout in Spain. J Med Econ. 2016;19(6):604-10.

10. Wertheimer A, Morlock R, Becker MA. A revised estimate of the burden of illness of gout. Curr Ther Res Clin Exp. 2013;75:1-4.

11. Rai SK, Burns LC, De Vera MA, Haji A, Giustini D, Choi HK. The economic burden of gout: a systematic review. Semin Arthritis Rheum. 2015;45(1):75-80.

12. Spaetgens B, Wijnands JM, van Durme C, van der Linden S, Boonen A. Cost of illness and determinants of costs among patients with gout. J Rheumatol. 2015;42(2):335-44

13. Schlesinger N. Treatment of acute gout. Rheum Dis Clin North Am. 2014;40(2):329-41.

14. Singh P, Bae MK, Fitzgerald S, Prakash JD, Kaldas S, Gogia M Oral Urate Lowering Therapies in Chronic Gout: A Systematic Review and Meta-analysis. Arthritis Rheumatol. 2011;63:1037.

15. Tabatabaei SM, Tabatabaei SMA, Zamani MM, Sabetkish N, Roshani F. Rhazes viewpoints about causes, diagnosis, treatment and prognosis of gout. J Med Ethics Hist Med. 2012;5.

16. Edwards NL. Febuxostat: a new treatment for hyperuricaemia in gout. Rheumatology. 2009;48(suppl_2):ii15-ii9.

17. Becker MA, Schumacher Jr HR, Wortmann RL, MacDonald PA, Eustace D, Palo WA, et al. Febuxostat compared with allopurinol in patients with hyperuricemia and gout. $\mathrm{N}$ Engl $\mathrm{J}$ Med. 2005;353(23):2450-61.

18. Schumacher HR, Becker MA, Wortmann RL, MacDonald PA, Hunt $\mathrm{B}$, Streit J, et al. Effects of febuxostat versus allopurinol and placebo in reducing serum urate in subjects with hyperuricemia and gout: a 28week, phase III, randomized, double-blind, parallel-group trial. Arthritis Care Res. 2008;59(11):1540-8.

19. Gandhi PK, Gentry WM, Ma Q, Bottorff MB. Cost-effectiveness analysis of allopurinol versus febuxostat in chronic gout patients: a US payer perspective. J Manag Care Spec Pharm. 2015;21(2):165-75.

20. Jutkowitz E, Choi HK, Pizzi LT, Kuntz KM. Cost-Effectiveness of Allopurinol and Febuxostat for the Management of GoutCostEffectiveness of Gout Therapies. Ann Intern Med. 2014;161(9):61726.

21. Mitri G, Wittbrodt ET, Turpin RS, Tidwell BA, Schulman KL. Cost Comparison of Urate-Lowering Therapies in Patients with Gout and Moderate-to-Severe Chronic Kidney Disease. J Manag Care Spec Pharm. 2016;22(4):326-36.

22. Smolen LJ, Gahn JC, Mitri G, Shiozawa A. Febuxostat in the management of gout: a cost-effectiveness analysis. J Med Econ. 2016;19(3):265-76.

23. Kydd AS, Seth R, Buchbinder R, Falzon L, Edwards CJ, van der Heijde DseM, et al. Urate-lowering therapy for the management of gout: a summary of 2 Cochrane reviews. J Rheumatol Suppl. 2014;92:33-41.

24. Drummond MF, Jefferson TO. Guidelines for authors and peer reviewers of economic submissions to the BMJ. The BMJ Economic Evaluation Working Party. BMJ. 1996;313(7052):275.

25. Langer A. A framework for assessing Health Economic Evaluation (HEE) quality appraisal instruments. BMC Health Serv Res. 2012;12(1):253

26. Singh JA, Akhras KS, Shiozawa A. Comparative effectiveness of urate lowering with febuxostat versus allopurinol in gout: analyses from large US managed care cohort. Arthritis Res Ther. 2015;17(1):120.
27. El-Zawawy H, Mandell BF. Managing gout: how is it different in patients with chronic kidney disease? Cleve Clin J Med. 2010;77(12):919-28.

28. Faruque LI, Ehteshami-Afshar A, Wiebe N, Tjosvold L, Homik J, Tonelli M. A systematic review and meta-analysis on the safety and efficacy of febuxostat versus allopurinol in chronic gout. Semin Arthritis Rheum. 2013;43(3):367-75

29. Beard SM, von Scheele BG, Nuki G, Pearson IV. Cost-effectiveness of febuxostat in chronic gout. Eur J Health Econ. 2014;15(5):453-63.

30. Stevenson M, Pandor A. Febuxostat for the management of hyperuricaemia in patients with gout. Pharmacoeconomics. 2011;29(2):133-40

31. Meltzer M, Pizzi LT, Jutkowitz E. Payer decision-making with limited comparative and cost effectiveness data: the case of new pharmacological treatments for gout. Evid Based Med. 2012;17(4):105-8. 
Appendix I. Search strategy

\begin{tabular}{|c|c|c|}
\hline Database & Search Strategy & Result \\
\hline Pubmed & $\begin{array}{l}\text { ((cost-effectiveness) AND (((Febuxostat) OR TEI 6720) OR Uloric)) AND ((Allopurinol OR Zyloprim OR Allohexal } \\
\text { OR Allohexan OR Alloprin OR Allopurin OR Allorin OR Allpargin OR Allural OR Apulonga OR Apurin OR Atisuri } \\
\text { OR Bleminol OR Caplenal OR Capurate OR Cellidrin OR Embarin OR Foligan OR Hamari OR Jenapurinol OR } \\
\text { Lopurin OR Lysuron OR Milurit OR Milurite OR Novopurol OR Progout OR Pan Quimica OR Pureduct OR Purinol } \\
\text { OR Remid OR Rimapurinol OR Roucol OR Suspendol OR Tipuric OR Uribenz OR Uridocid OR Uripurinol OR } \\
\text { Urosin OR Urtias OR Xanthomax OR Xanturic OR Zyloprim OR Zyloric)) }\end{array}$ & 17 \\
\hline $\begin{array}{l}\text { Cochrane } \\
\text { CENTRAL }\end{array}$ & $\begin{array}{l}\text { '(Allopurinol OR Zyloprim OR Allohexal OR Allohexan OR Alloprin OR Allopurin OR Allorin OR Allpargin OR } \\
\text { Allural OR Apulonga OR Apurin OR Atisuri OR Bleminol OR Caplenal OR Capurate OR Cellidrin OR Embarin OR } \\
\text { Foligan OR Hamari OR Jenapurinol OR Lopurin OR Lysuron OR Milurit OR Milurite OR Novopurol OR Progout } \\
\text { OR "Pan Quimica" OR Pureduct OR Purinol OR Remid OR Rimapurinol OR Roucol OR Suspendol OR Tipuric OR } \\
\text { Uribenz OR Uridocid OR Uripurinol OR Urosin OR Urtias OR Xanthomax OR Xanturic OR Zyloprim OR Zyloric) } \\
\text { AND febuxostat AND ("Cost Benefit" OR "Cost Effectiveness" OR "Cost Utility" OR "Economic Evaluation" OR } \\
\text { "Marginal Analysis") AND Gout in Title, Abstract, Keywords in Economic Evaluations' }\end{array}$ & 2 \\
\hline $\begin{array}{l}\text { ISI-Web Of } \\
\text { Science }\end{array}$ & $\begin{array}{l}\text { TOPIC: (Allopurinol OR Zyloprim OR Allohexal OR Allohexan OR Alloprin OR Allopurin OR Allorin OR All- } \\
\text { pargin OR Allural OR Apulonga OR Apurin OR Atisuri OR Bleminol OR Caplenal OR Capurate OR Cellidrin OR } \\
\text { Embarin OR Foligan OR Hamari OR Jenapurinol OR Lopurin OR Lysuron OR Milurit OR Milurite OR Novopurol } \\
\text { OR Progout OR Pan Quimica OR Pureduct OR Purinol OR Remid OR Rimapurinol OR Rouciol OR Suspendol OR } \\
\text { Tipuric OR Uribenz OR Uridocid OR Uripurinol OR Urosin OR Urtias OR Xanthomax OR Xanturic OR Zyloprim } \\
\text { OR Zyloric) AND TOPIC: (Gout) AND TOPIC: (febuxostat) AND TOPIC: (Cost Benefit OR Cost Effectiveness OR } \\
\text { Cost Utility OR Economic Evaluation OR Marginal Analysis) }\end{array}$ & 19 \\
\hline Scopus & $\begin{array}{l}\text { TITLE-ABS-KEY(Allopurinol OR Zyloprim OR Allohexal OR Allohexan OR Alloprin OR Allopurin OR Allorin OR } \\
\text { Allpargin OR Allural OR Apulonga OR Apurin OR Atisuri OR Bleminol OR Caplenal OR Capurate OR Cellidrin OR } \\
\text { Embarin OR Foligan OR Hamari OR Jenapurinol OR Lopurin OR Lysuron OR Milurit OR Milurite OR Novopurol } \\
\text { OR Progout OR "Pan Quimica" OR Pureduct OR Purinol OR Remid OR Rimapurinol OR Roucol OR Suspendol OR } \\
\text { Tipuric OR Uribenz OR Uridocid OR Uripurinol OR Urosin OR Urtias OR Xanthomax OR Xanturic OR Zyloprim } \\
\text { OR Zyloric) AND TITLE-ABS-KEY(febuxostat ) AND TITLE-ABS-KEY("Cost Benefit" OR "Cost Effectiveness" } \\
\text { OR "Cost-Utility" OR "Economic Evaluation" OR "Marginal Analysis") }\end{array}$ & 31 \\
\hline Embase & $\begin{array}{l}\text { allopurinol:ab,ti OR allohexal:ab,ti OR allohexan:ab,ti OR alloprin:ab,ti OR allopurin:ab,tii OR allorin:ab,ti OR } \\
\text { allpargin:ab,ti OR allural:ab,ti OR apulonga:ab,ti OR apurin:ab,ti OR atisuri:ab,ti OR bleminol:ab,ti OR caple- } \\
\text { nal:ab,ti OR capurate:ab,ti OR cellidrin:ab,ti OR embarin:ab,ti OR foligan:ab,ti OR hamari:ab,ti OR jenapuri- } \\
\text { nol:ab,ti OR lopurin:ab,ti OR lysuron:ab,ti OR milurit:ab,ti OR milurite:ab,ti OR novopurol:ab,ti OR progout:ab,ti } \\
\text { OR 'pan quimica':ab,ti OR pureduct:ab,ti OR purinol:ab,ti OR remid:ab,ti OR rimapurinol:ab,ti OR roucol:ab,ti } \\
\text { OR suspendol:ab,ti OR tipuric:ab,ti OR uribenz:ab,ti OR uridocid:ab,ti OR uripurinol:ab,ti OR urosin:ab,ti OR } \\
\text { urtias:ab,ti OR xanthomax:ab,ti OR xanturic:ab,ti OR zyloprim:ab,ti OR zyloric:ab,ti AND febuxostat:ab,ti AND } \\
\text { gout:ab,ti AND ('cost-benefit analysis':ab,ti OR 'cost benefit':ab,ti OR 'cost benefit analysis':ab,ti OR 'cost effec- } \\
\text { tiveness':ab,ti OR 'cost-benefit data':ab,ti OR 'cost-effectiveness analysis':ab,ti OR 'cost-utility analysis':ab,ti OR } \\
\text { 'economic evaluation':ab,ti OR 'marginal analysis':ab,ti }\end{array}$ & 20 \\
\hline
\end{tabular}

